\title{
On Detrending and Cyclical Asymmetry
}

\author{
Zacharias Psaradakis ${ }^{\mathrm{a}, 1}$ and Martin Sola ${ }^{\mathrm{a}, \mathrm{b}}$ \\ ${ }^{\text {a }}$ School of Economics, Mathematics and Statistics, Birkbeck College, 7-15 Gresse Street, \\ London W1T $1 \mathrm{LL}$, United Kingdom \\ ${ }^{\mathrm{b}}$ Departamento de Economia, Universidad Torcuato Di Tella, Minhones 2177, C1428ATG Buenos Aires, \\ Argentina
}

\begin{abstract}
This paper considers the issue of testing for symmetry of the business cycle. It is demonstrated that findings of symmetry should be interpreted with caution since tests tend to have low power to detect asymmetries when applied to data that have been filtered to isolate their stationary business-cycle component. This implies that asymmetries are likely to be detected in practice only when they are particularly prominent. An empirical application examines the properties of the cyclical component of real GDP from the G7 countries.
\end{abstract}

Keywords: Asymmetry; Bootstrap; Business cycle; Detrending; Markov chain; Skewness; Time-reversibility.

JEL Classification: C52; E32.

First draft: April 2001; this version: April 2002

\section{INTRODUCTION}

Since the early work of Keynes (1936) and Burns and Mitchell (1946), the question of whether real economic variables behave asymmetrically over the phases of the business cycle has attracted much interest in theoretical and empirical macroeconomics. Such investigations are an important step towards establishing the 'stylized facts' associated with business-cycle fluctuations and in selecting statistical models that are appropriate for the analysis of economic time series. The understanding of stylized facts relating to asymmetry is essential for at least four reasons. First, as Canova (1998) observes, stylized facts provide a set of empirical regularities that any numerical version of a theoretical macroeconomic model that purports to be of empirically relevance should account for. Real business-cycle models, for example, can be successfully calibrated to match a variety of empirical regularities and, if asymmetry is one of these regularities, models need to be modified to allow for asymmetric behaviour. Second, since there appears to be a strong link between the behaviour of many financial variables and the stage and characteristics of the business cycle (see, inter alia, Ferson and Merrick, 1987; Fama and French, 1989; Fama, 1990), ignoring the latter will most likely lead to erroneous conclusions. Third, as aptly pointed out by McQueen and Thorley (1993) and Sichel (1993), the existence of asymmetry imposes constraints on the class of statistical models that can adequately describe the dynamic behaviour of economic and financial variables. For instance, linear time-series models with symmetrically distributed innovations are unlikely to provide valid data descriptions or accurate forecasts in the presence of asymmetries. Such model misspecifications can, in turn, give rise to misleading policy conclusions, as discussed

${ }^{1}$ Corresponding author. E-mail: z.psaradakis@bbk.ac.uk; fax: +44 20 76316416; tel.: +44 2076316415 . 
in Boldin (1999). Finally, asymmetry has important implications for the construction of theoretical models of economic behaviour. Its existence makes unattractive many models that include implicit or explicit symmetry assumptions (as is the case with many rational expectations models) and necessitates the development of models that can generate asymmetric behaviour endogenously (see, inter alia, Caballero and Engel, 1991; Acemoglu and Scott, 1997; Chalkley and Lee, 1998).

Following DeLong and Summers (1986) and Sichel (1993), much of the work on business-cycle asymmetry characterizes the latter by the distributional asymmetry of data that have been filtered to remove their trend component (i.e. fluctuations displaying low frequencies). Others define asymmetry in terms of the transition probabilities of a Markov-chain description of the business cycle (Neftçi, 1984; McQueen and Thorley, 1993), asymmetric persistence to shocks (Beaudry and Koop, 1993), or time-irreversibility of time series associated with the business cycle (Ramsey and Rothman, 1996). An important issue that arises in this literature is that of detrending/filtering of time series that exhibit secular growth to extract their cyclical component (see, e.g., Falk, 1986; Westlund and Öhlén, 1991; Sichel, 1993; Giles, 1997; Verbrugge, 1997; Canova, 1998; Razzak, 2001). Such filtering is indeed essential if any detected asymmetries are to be considered a characteristic of cyclical fluctuations, and its use has been standard practice in business-cycle research. For example, empirical business-cycle regularities are almost exclusively analyzed using filtered data, with the more sophisticated researchers making use of a variety of prefiltering methods in an attempt to establish the robustness or otherwise of stylized facts with respect to different ways of measuring the business cycle (e.g., Canova, 1998). Filtered data are also used extensively for the calibration of theoretical real business-cycle models, where one must distinguish between transitory shocks which leave the steady state of the economy unaltered and permanent shocks which have lasting long-term effects on the economy (and are not, therefore, very pertinent for business cycle analysis). Since stationary data is required for the analysis of transitory shocks, detrending filters are typically used as a means of isolating the cyclical components of the relevant time series and inducing stationarity.

It must be emphasized that the alternative practice of analyzing the properties of the business cycle using first-differenced data leaves much to be desired. Examples of this approach are Neftçi (1984) and McQueen and Thorley (1993), who use a Markov-chain model for first-differenced data to test for cyclical asymmetry, and more recently Harding and Pagan (2002), who put forward a related method. Although such studies claim to present evidence of cyclical asymmetry, their measure of the 'business cycle' arguably has little to do with what researchers typically think of as business-cycle fluctuations. ${ }^{2}$ The first-difference filter is undoubtedly capable of inducing stationarity in many macroeconomic time series but few would argue that it isolates only the business-cycle component of the data. Indeed, this filter is known to put strong emphasis on high-frequency components while down-weighting lower frequencies (cf. Baxter and King, 1999). ${ }^{3}$ The criticism is also pertinent for studies that make use of Markov-switching models à la Hamilton (1989), models which have been used very successfully to establish business-cycle turning points and analyze the potential power of different monetary variables in predicting booms and recessions. It should

\footnotetext{
${ }^{2}$ Burns and Mitchell (1946), for example, specified the business cycle to be fluctuations with duration between 6 and 32 quarters.

${ }^{3}$ The use of first-differenced data to analyze asymmetry was also criticized by Falk (1986), who argued that, for a time series with a positive trend, a downturn in the cyclical component may occur without the series showing any negative change, thus biasing tests in favour of asymmetry. Falk's suggestion was to carry out a test after detrending the data.
} 
be borne in mind, however, that most of the empirical applications based on such models use first-differenced data, so some inferences about the cyclical properties of the relevant economic variables may be misleading. Generalizations of Markov-switching models along the lines of Kim and Yoo (1995) -where the cyclical component is modelled separately- do not suffer from this criticism and could be used to study business-cycle asymmetry.

The aim of the present paper is to demonstrate that stylized facts relating to asymmetries in economic variables should always be interpreted with caution since data detrending can lead researchers to report spurious symmetric behaviour. More specifically, we investigate the properties of some popular symmetry tests applied to data that have been detrended using three different methods, namely the Hodrick-Prescott (HP) filter (Hodrick and Prescott, 1997), a band-pass (BP) filter (Baxter and King, 1999), and a procedure based on the Beveridge-Nelson (BN) decomposition of a time series (Beveridge and Nelson, 1981). All three detrending procedures share the desirable property that, since they have linear representations, they cannot induce asymmetry if none is present in the data. In the light of the widespread use of these methods in the business-cycle literature, ${ }^{4}$ it seems particularly important to examine the effects that data-filtering might have on the properties of tests for cyclical asymmetry. The tests we consider are a skewness-based test, a Markov-chain test, and a test for time-reversibility.

Our analysis demonstrates that, when the cyclical component of a time series is extracted by means of the HP, BP or BN procedures, much information about asymmetry in the true cyclical component is lost, resulting in tests having little power to detect deviations form symmetry. ${ }^{5}$ This implies that it is particularly important not to uncritically interpret failure to detect asymmetries in detrended time series as evidence in favour of symmetric cyclical behaviour. Conversely, whenever asymmetry of the cycle is established using the familiar detrending methods, this can be taken as strong evidence in favour of asymmetry.

The remainder of the paper is organized as follows. Section 2 discusses the symmetry tests of interest and describes briefly the detrending procedures. Section 3 presents Monte Carlo evidence on the performance of symmetry tests in the case of asymmetric data-generating mechanisms. In Section 4 we investigate the patterns of asymmetry in real GDP series from the Group of Seven (G7) countries. Section 5 summarizes and concludes.

\section{DETRENDING AND TESTING FOR SYMMETRY}

In an influential paper, Sichel (1993) distinguished between two types of business-cycle asymmetry: 'deepness' (troughs are deeper than peaks are tall) and 'steepness' (contractions are steeper than expansions). These asymmetries are characterized by the distributional asymmetry of the level and of the first difference, respectively, of the cyclical component of the time series of interest. As Ramsey and Rothman (1996) observed, deepness is an example of 'transversal' asymmetry (i.e., asymmetry that is orthogonal to the direction of the movement of the business cycle), whereas steepness is an example of 'lognitudinal' asymmetry (i.e., asymmetry in the direction of the movement of the business cycle). The issues of statistical identification of asymmetry and of estimation of the latent cyclical component are, therefore, of central interest.

\footnotetext{
${ }^{4}$ The HP filter has been by far the most popular among business-cycle analysts despite having been criticized by many for a number of shortcomings (see, inter alia, Harvey and Jaeger, 1993; King and Rebelo, 1993; Cogley and Nason, 1995; Maravall, 1995; Christiano and den Haan, 1996).

${ }^{5}$ McNevin and Neftçi (1992) also raised the issue of linear detrending having an adverse effect on the power of a Markov-chain test for symmetry of the business cycle.
} 


\subsection{Tests for Cyclical Symmetry}

\subsubsection{Skewness-Based Test}

A simple test for symmetry of the (one-dimensional) marginal distribution of a strictly stationary random process $\left\{y_{t}\right\}$ may be based on the coefficient of skewness $\gamma_{1}:=\kappa_{2}^{-3 / 2} \kappa_{3}$, where $\kappa_{r}$ is the $r$ th cumulant of $y_{t}$. If observations $\left(y_{1}, \ldots, y_{n}\right)$ from a realization of $\left\{y_{t}\right\}$ are available, $\gamma_{1}$ is typically estimated by the empirical skewness

$$
\widetilde{\gamma}_{1}:=\left\{n^{-1} \sum_{t=1}^{n}\left(y_{t}-\bar{y}\right)^{2}\right\}^{-3 / 2}\left\{n^{-1} \sum_{t=1}^{n}\left(y_{t}-\bar{y}\right)^{3}\right\},
$$

where $\bar{y}:=n^{-1} \sum_{t=1}^{n} y_{t}$. Gasser (1975) showed that, when $\left\{y_{t}\right\}$ is a Gaussian process with absolutely summable autocovariances, $\widetilde{\gamma}_{1}$ is asymptotically normal with mean zero and variance $6 n^{-1} \sum_{\tau=-\infty}^{\infty} \rho_{\tau}^{3}+O\left(n^{-2}\right)$, where $\rho_{\tau}:=\operatorname{Corr}\left[y_{t+\tau}, y_{t}\right]$. Therefore, a test for symmetry can be based on the statistic

$$
\mathcal{S}:=\left(6 n^{-1} \sum_{\tau=-k}^{k} \widehat{\rho}_{\tau}^{3}\right)^{-1} \widetilde{\gamma}_{1}^{2}
$$

where

$$
\widehat{\rho}_{\tau}:=\left\{n^{-1} \sum_{t=1}^{n}\left(y_{t}-\bar{y}\right)^{2}\right\}^{-1}\left\{n^{-1} \sum_{t=1}^{n-|\tau|}\left(y_{t+|\tau|}-\bar{y}\right)\left(y_{t}-\bar{y}\right)\right\}, \quad|\tau| \leqslant n-1,
$$

and $k$ is a suitably chosen nonnegative integer. For large sample sizes and large $k$, the contribution in the asymptotic variance of $\widetilde{\gamma}_{1}$ of correlations such as $\rho_{\tau}$ with $\tau>k$ can be expected to be small and $\mathcal{S}$ will be approximately distributed as a $\chi_{1}^{2}$ variate.

An alternative, popular way of constructing an autocorrelation-robust test for symmetry based on $\widetilde{\gamma}_{1}$ is to use a kernel estimate of the asymptotic variance of $\widetilde{\gamma}_{1}$ (see, among many others, Sichel, 1993; Giles, 1997; Speight and McMillan, 1998). However, kernel estimators can be substantially biased in small and moderately sized samples, resulting in symmetry tests which have finite-sample properties that are very different from those predicted on the basis of large-sample theory. To illustrate the difficulties involved, we shall discuss the results of some sampling experiment designed to shed light on the relative performance of the two alternative variance estimators.

In our experiments, 2,500 time series $\left\{y_{t}\right\}$ of length $n \in\{100,200\}$ were generated according to the following models:

$$
\begin{array}{ll}
\mathrm{M}_{1}: & y_{t}=u_{t} \\
\mathrm{M}_{2}: & y_{t}=0.4 y_{t-1}-0.5 y_{t-2}+u_{t} \\
\mathrm{M}_{3}: & y_{t}=1.1 y_{t-1}-0.85 y_{t-2}+u_{t} \\
\mathrm{M}_{4}: & y_{t}=u_{t}+0.24 u_{t-1}+0.15 u_{t-2} \\
\mathrm{M}_{5}: & y_{t}=-1.27 y_{t-1}-0.81 y_{t-2}+u_{t}+1.27 u_{t-1}-0.81 u_{t-2}
\end{array}
$$

with $\left\{u_{t}\right\}$ being independent, identically distributed (i.i.d.) $N(0,1)$ variates. ${ }^{6}$ These models were selected to represent a variety of dynamic behaviour but are not intended to be exhaustive. ${ }^{7}$ For

\footnotetext{
${ }^{6}$ Throughout the paper, artificial time series of length $n+100$ are generated by setting initial values to zero and then discarding the first 100 pseudo-data points to eliminate start-up effects.

${ }^{7}$ Models $\mathrm{M}_{1}, \mathrm{M}_{2}, \mathrm{M}_{3}$ and $\mathrm{M}_{5}$ were used in Gasser (1975), while $\mathrm{M}_{4}$ describes well the US real GDP growth rate (cf. Section 4).
} 
each artificial time series, the asymptotic variance of $\widetilde{\gamma}_{1}$ was estimated by using: (a) the estimator $6 n^{-1} \sum_{\tau=-k}^{k} \widehat{\rho}_{\tau}^{3}$ proposed by Gasser (1975), with $k$ chosen as the largest integer in the interval $[1, n / 3]$ for which $\left|\widehat{\rho}_{k}\right|>1.96 n^{-1 / 2}\left(1+2 \sum_{\tau=1}^{k-1} \widehat{\rho}_{\tau}^{2}\right)^{1 / 2}$; (b) the prewhitened quadratic spectral kernel estimator of Andrews and Monahan (1992) with the data-dependent bandwidth given in their equations (3.5) and (3.6).

Table 1 reports the Monte Carlo sampling variance of $\widetilde{\gamma}_{1}$ and the average estimated variance over the 2,500 replications, along with the rejection frequency of corresponding 0.05-level tests for symmetry based on $\widetilde{\gamma}_{1}^{2}$. The superiority of the Gasser-type variance estimator over the kernel estimator is very clear, the latter estimator being upwards biased for the true sampling variance. In fact, the bias of the kernel estimator is so substantial that a test for symmetry that relies on it is conservative to the extreme, having a zero empirical type-I error probability in most cases. In sharp contrast, a test constructed using a Gasser-type variance estimate has empirical rejection frequency which is rarely significantly different from the nominal 0.05 value. In the light of this evidence, only symmetry tests based on the statistic given in (1) will be considered in the remainder of the paper.

It should be borne in mind, however, that the $\chi_{1}^{2}$ large-sample approximation to the sampling distribution of $\mathcal{S}$ is valid when the marginal distribution of $\left\{y_{t}\right\}$ is Gaussian rather than merely symmetric. It is possible, therefore, that the $\chi_{1}^{2}$ approximation will not be very accurate in symmetric but non-Gaussian situations. Experimentation with various ARMA models revealed this to be the case for some types of non-Gaussian innovations (e.g., Student- $t$ innovations), the empirical type-I error probability of the test tending to be higher than the nominal level. As a means of overcoming these difficulties when symmetry rather than Gaussianity is the hypothesis of interest, we propose to use bootstrap methods to obtain an approximation to the null sampling distribution of $\mathcal{S}$. Note, however, that standard bootstrap procedures involving random data resampling are inappropriate in our case since they are based on the assumption of i.i.d. data. Our suggestion is to use a symmetric version of the sieve bootstrap procedure discussed in Bühlmann (1997) and Kreiss (1997), which allows for data that are generated by a linear processes (a description of the procedure can be found in the Appendix). The asymptotic validity of a sieve bootstrap for a symmetry test based on $\mathcal{S}$ follows from Bühlmann (1997) and Kreiss (1997), where consistency for smooth functions of linear statistics is established. ${ }^{8}$

Tests for symmetry constructed using bootstrap critical values appear to work very well. For instance, for artificial time series of length $n=100$ from model $\mathrm{M}_{2}$, the Monte Carlo rejection frequency of the test is $0.060,0.054$ and 0.044 when $\left\{u_{t}\right\}$ come from the double-exponential distribution, the Student- $t$ distribution with 8 degrees of freedom, or the logistic distribution, respectively. ${ }^{9}$ The corresponding rejection frequencies for pseudo-data from model $\mathrm{M}_{4}$ are 0.058 , 0.052 and 0.060 , while the corresponding figures for model $\mathrm{M}_{5}$ are $0.056,0.042$ and 0.043 . The good performance of the bootstrap test in the last case is particularly noteworthy since the ARMA process defined by $\mathrm{M}_{5}$ is noninvertible and hence does not belong to the class of processes for which the sieve bootstrap is designed. ${ }^{10}$

\footnotetext{
${ }^{8}$ First-order asymptotic correctness of the sieve bootstrap requires that: (a) the data-generating process admits a stable infinite-order autoregressive representation with one-summable coefficients and i.i.d. innovations with finite eighth moment; (b) the order of the autoregressive model fitted to the data increases with $n$ but is of smaller order than $(n / \log n)^{1 / 4}$. It is not difficult to show that resampling from the symmetrized empirical distribution of the residuals from of an autoregressive approximation (cf. Appendix) does not affect the asymptotic validity of the method.

${ }^{9}$ All distributions were rescaled to have unit variance.

${ }^{10} \mathrm{An}$ explanation for this finding may lie with the results in Bickel and Bühlmann (1997), which show that the closure (with respect to certain metrics) of the class of infinite-order moving-average or infinite-order autoregressive processes is fairly large. This implies that the sieve bootstrap is likely to yield satisfactory results even for processes which do not admit an autoregressive representation.
} 


\subsubsection{Markov-Chain Test}

Neftçi's (1984) test procedure is based on the observation that runs of increasing values of an asymmetric time series are more or less likely to persist than are runs of decreasing values. Hence asymmetry over the business cycle can be characterized in terms of transition probabilities associated with the signs of changes in the cyclical component of the time series of interest. If $\left\{y_{t}\right\}$ denotes this cyclical component, let

$$
I_{t}:=\mathbf{1}\left(\Delta y_{t}>0\right)-\mathbf{1}\left(\Delta y_{t} \leqslant 0\right)
$$

where $\Delta$ is the usual first-difference operator and $\mathbf{1}(A)$ is the indicator random variable of the event $A$. Neftçi assumes that the random sequence $\left\{I_{t}\right\}$ is a second-order Markov chain on $\{1,-1\}$ with stationary transition probabilities (see also Falk, 1986; Sichel, 1989). Under this assumption, business-cycle asymmetry implies that $p_{11} \neq p_{22}$, where $p_{11}:=\operatorname{Pr}\left[I_{t}=1 \mid I_{t-1}=1, I_{t-2}=1\right]$ and $p_{22}:=\operatorname{Pr}\left[I_{t}=-1 \mid I_{t-1}=-1, I_{t-2}=-1\right] .{ }^{11}$ Hence, a test for asymmetry can be based on the Studentized statistic

$$
\mathcal{C}:=\left(\widehat{p}_{11}-\widehat{p}_{22}\right) / \widehat{\omega}
$$

where $\widehat{p}_{11}$ and $\widehat{p}_{22}$ are the maximum-likelihood estimates of $p_{11}$ and $p_{22}$, respectively, and $\widehat{\omega}$ is a consistent estimate of the standard deviation of $\left(\widehat{p}_{11}-\widehat{p}_{22}\right)$. The statistic $\mathcal{C}$ will be asymptotically distributed as an $N(0,1)$ variate under the null hypothesis $p_{11}=p_{22}$ implied by symmetry of the business cycle.

\subsubsection{Time-Reversibility Test}

Ramsey and Rothman (1996) observed that, while transversally asymmetric time series are timereversible (i.e., their finite-dimensional distributions are invariant to the reversal of time indices), lognitudinally asymmetric time series are time-irreversible. One can, therefore, test for lognitudinal business-cycle asymmetry by using a test for time-reversibility.

The test for time-reversibility considered here is due to Chen et al. (2000), which exploits the implication that the marginal distributions of the differences of a time-reversible process are symmetric. ${ }^{12}$ If, as before, $\left\{y_{t}\right\}$ is the cyclical component of the time series of interest, the test is based on the statistic

$$
\mathcal{R}_{\ell}:=\left\{(n-\ell) \widehat{\sigma}_{\ell}^{2}\right\}^{-1 / 2} \sum_{t=\ell+1}^{n} \psi\left(s_{t, \ell}\right)
$$

where $s_{t, \ell}:=y_{t}-y_{t-\ell}(\ell \in \mathbb{N}), \psi(z)=\int_{0}^{\infty} \sin (v z) g(v) \mathrm{d} v(z \in \mathbb{R}), g$ is a weighting function satisfying $\int_{0}^{\infty} g(v) \mathrm{d} v<\infty$, and $\widehat{\sigma}_{\ell}^{2}$ is a consistent estimator of $\sigma_{\ell}^{2}:=\lim _{n \rightarrow \infty} \operatorname{Var}\left[(n-\ell)^{-1 / 2} \sum_{t=\ell+1}^{n} \psi\left(s_{t, \ell}\right)\right]$. Under the null hypothesis that $\left\{y_{t}\right\}$ is time-reversible, the distribution of $s_{t, \ell}$ is symmetric about the origin and $\mathcal{R}_{\ell}$ is asymptotically distributed as an $N(0,1)$ variate. $^{13}$

In subsequent analysis, we take $g$ to be the density function of the exponential distribution with mean $\beta$, so that $\psi(z)=\beta z /\left(1+\beta^{2} z^{2}\right)$. Following Chen et al. (2000), we set $\beta$ equal to the reciprocal

\footnotetext{
${ }^{11}$ Like business-cycle steepness, the asymmetry that is implied by $p_{11} \neq p_{22}$ is an example of lognitudinal asymmetry (see Ramsey and Rothman, 1996).

${ }^{12}$ This test is preferable to the test of Ramsey and Rothman (1996) since, unlike the latter, it does not focus only on the third moment of the marginal distribution of the time series under test and does not even require the moments of this distribution to exist.

${ }^{13}$ Notice that the $\mathcal{R}_{\ell}$ test is essentially a test for steepness when $\ell=1$ since the null hypothesis implies symmetry of the distribution of $\Delta y_{t}$.
} 
of the sample standard deviation of $\left\{s_{t, \ell}\right\}$. An estimate of $\sigma_{\ell}^{2}$ is obtained nonparametrically as

$$
\widehat{\sigma}_{\ell}^{2}=(n-\ell)^{-1}\left\{\sum_{t=\ell+1}^{n}\left[\psi\left(s_{t, \ell}\right)-\bar{\psi}_{\ell}\right]^{2}+2 \sum_{\tau=1}^{n-\ell-1} K(\tau) \sum_{t=1}^{n-\tau}\left[\psi\left(s_{t+\tau, \ell}\right)-\bar{\psi}_{\ell}\right]\left[\psi\left(s_{t, \ell}\right)-\bar{\psi}_{\ell}\right]\right\}
$$

where

$$
K(\tau):=\left[1-\tau(n-\ell)^{-1}\right]\left[1-\frac{1}{2}(n-\ell)^{-1 / 3}\right]^{\tau}+\tau(n-\ell)^{-1}\left[1-\frac{1}{2}(n-\ell)^{-1 / 3}\right]^{n-\ell-\tau},
$$

and $\bar{\psi}_{\ell}:=(n-\ell)^{-1} \sum_{t=\ell+1}^{n} \psi\left(s_{t, \ell}\right)$.

\subsection{Detrending}

In order to test for cyclical symmetry, the statistics $\mathcal{S}, \mathcal{C}$ and $\mathcal{R}_{\ell}$ must be used in conjunction with an estimate of the latent stationary cyclical component of the time series of interest. ${ }^{14}$ In this paper, we focus on three popular methods for extracting the cyclical component of a time series, namely the HP, BN and BP methods. In what follows, we shall use $\left\{x_{t}\right\},\left\{\xi_{t}\right\}$ and $\left\{y_{t}\right\}$ to denote, respectively, the observed time series, its nonstationary secular component, and its stationary cyclical component.

\subsubsection{The Hodrick-Prescott Filter}

The HP detrending method is based on the assumption that the two components $\left\{\xi_{t}\right\}_{t=1}^{n}$ and $\left\{y_{t}\right\}_{t=1}^{n}$ of the observed time series $\left\{x_{t}\right\}_{t=1}^{n}$ are statistically independent and $\left\{\xi_{t}\right\}_{t=1}^{n}$ evolves smoothly over time. Then, an estimate $\left\{\widehat{\xi}_{t}\right\}_{t=1}^{n}$ of the trend component is obtained as the solution to the convex optimization problem:

$$
\min _{\left\{\xi_{t}\right\}_{t=1}^{n}}\left\{\sum_{t=1}^{n}\left(x_{t}-\xi_{t}\right)^{2}+\lambda \sum_{t=2}^{n-1}\left[\left(\xi_{t+1}-\xi_{t}\right)-\left(\xi_{t}-\xi_{t-1}\right)\right]^{2}\right\} .
$$

In (4), $\lambda>0$ is a smoothing parameter which regulates the trade-off between the objectives of goodness-of-fit (small $\left.\left(x_{t}-\xi_{t}\right)^{2}\right)$ and smoothness (small $\left.\left(\xi_{t+1}-2 \xi_{t}+\xi_{t-1}\right)^{2}\right)$. In practice, $\lambda=1,600$ is typically used for quarterly data, while $\lambda=6.25$ and $\lambda=129,600$ appear to be sensible choices for monthly and annual data, respectively (cf. Ravn and Uhlig, 1997). The detrended series is then defined as $\widehat{y}_{t}^{\mathrm{HP}}:=x_{t}-\widehat{\xi}_{t}(t=1, \ldots, n)$. As shown in King and Rebelo (1993), when $\lambda=1,600$,

$$
\widehat{y}_{t}^{\mathrm{HP}} \underset{n \rightarrow \infty}{\longrightarrow}\left\{\frac{0.7794(1-L)^{2}\left(1-L^{-1}\right)^{2}}{g(L) g\left(L^{-1}\right)}\right\} x_{t}
$$

where $g(L):=1-1.7771 L+0.7994 L^{2}$ and $L$ is the lag operator. It follows, therefore, that the HP filter will render covariance-stationary any time series which is integrated of order up to 4 . Furthermore, the HP filter with $\lambda=1,600$ is a close approximation to a high-pass filter with cut-off frequency $\pi / 16$, so it typically removes components of the data with periodicity greater than 32 quarters.

\subsubsection{The Band-Pass Filter}

The BP filter discussed in Baxter and King (1999) isolates the cyclical component of a time series by suppressing periodic components with frequencies which do not correspond to the researcher's definition of business-cycle fluctuations. An ideal BP filter has a time-domain representation which

\footnotetext{
${ }^{14} \mathrm{~A}$ skewness-based test for deepness involves the estimate of the cyclical component itself, whereas a test for steepness involves the first-difference of this estimate.
} 
takes the form of a symmetric, absolutely summable, time-invariant linear filter $H^{*}:=\left\{h_{j}^{*}\right\}_{j=0}^{\infty}$, i.e.,

$$
y_{t}^{\mathrm{BP}}:=\sum_{j=-\infty}^{\infty} h_{|j|}^{*} x_{t-j} .
$$

For any desired 'band' of business-cycle frequencies $\left[\omega_{1}, \omega_{2}\right] \subset[0, \pi]$, the weights of the filter are chosen so that the frequency-response function, $\Gamma(\cdot)$, of $H^{*}$ is

$$
\Gamma(\omega):=\sum_{j=-\infty}^{\infty} h_{|j|}^{*} e^{-\mathrm{i} \omega j}= \begin{cases}1, & \omega_{1} \leqslant|\omega| \leqslant \omega_{2} \\ 0, & \text { otherwise }\end{cases}
$$

(i $:=\sqrt{-1}$ ). In practice, one may use an $m$ th-order approximation $H_{m}:=\left\{h_{j}\right\}_{j=0}^{m}$ to the ideal filter $H^{*}$, so that the BP-filtered series is obtained as

$$
\widehat{y}_{t}^{\mathrm{BP}}:=\sum_{j=-m}^{m} h_{|j|} x_{t-j}, \quad t=m+1, \ldots, n-m
$$

where $h_{j}:=h_{j}^{*}-(1+2 m)^{-1} \sum_{j=-m}^{m} h_{|j|}^{*}$ for $j=0,1, \ldots, m$. Since $\sum_{j=-m}^{m} h_{|j|}=0$, Baxter and King (1999) show that the BP filter $H_{m}$ will render covariance-stationary any time series which is integrated of order up to 2 . For quarterly data, they recommend setting $m=12, \omega_{1}=\pi / 16$ and $\omega_{2}=\pi / 3$. Their choice of $\left(\omega_{1}, \omega_{2}\right)$ implies that only components with periodicity between 6 and 32 quarters are retained, which is consistent with the National Bureau of Economic Research (NBER) definition of a business cycle.

\subsubsection{The Beveridge-Nelson Procedure}

The basic assumption underlying the procedure of Beveridge and Nelson (1981) is that $\left\{x_{t}\right\}_{t=1}^{n}$ is a realization from an $\operatorname{ARIMA}(p, 1, q)$ process,

$$
\Delta x_{t}-c=\sum_{j=1}^{p} \varphi_{j}\left(\Delta x_{t-j}-c\right)+\sum_{j=0}^{q} \vartheta_{j} \varepsilon_{t-j}
$$

where $\vartheta_{0}:=1,\left\{\varepsilon_{t}\right\}$ is a zero-mean white noise, and $\varphi(z):=1-\sum_{j=1}^{p} \varphi_{j} z^{j} \neq 0$ for all $|z| \leqslant 1$. Such a process may be represented in terms of a stochastic trend and a stationary cyclical component which are perfectly correlated. The latter component is defined as (cf. Newbold, 1990)

$$
y_{t}^{\mathrm{BN}}:=\lim _{m \rightarrow \infty} \sum_{j=1}^{m} \widehat{w}_{t}(j)=\sum_{j=1}^{q} \widehat{w}_{t}(j)+\varphi(1)^{-1} \sum_{j=1}^{p} \sum_{i=j}^{p} \varphi_{i} \widehat{w}_{t}(q-j+1),
$$

where $\widehat{w}_{t}(j)$ is the best linear predictor of $w_{t+j}:=\Delta x_{t+j}-c$ based on $\left\{x_{1}, \ldots, x_{t}\right\}$. In practice, an estimate $\widehat{y}_{t}^{\mathrm{BN}}$ of $y_{t}^{\mathrm{BN}}$ is obtained using estimates of the unknown parameters in (5) and forecasts $\widehat{w}_{t}(j)$ constructed on the basis of these estimates.

\section{A SIMULATION STUDY}

In this section, we attempt to shed some light on the effect of detrending on the properties of symmetry tests by means of a simulation study. The data-generating mechanism used for the experiments is the following linear unobserved-components model:

$$
\begin{aligned}
x_{t} & =\xi_{t}+y_{t}, \\
\xi_{t} & =0.01+\xi_{t-1}+0.01 \eta_{t}, \\
y_{t} & =1.5 y_{t-1}-0.58 y_{t-2}+0.01 u_{t},
\end{aligned}
$$


where $\left\{\eta_{t}\right\}$ are i.i.d. $N(0,1)$ random variables and $\left\{u_{t}\right\}$ are i.i.d. random variables, independent of $\left\{\eta_{t}\right\}$, with zero mean and unit variance. ${ }^{15}$ Notice that the stationary component of a time series generated according to (6)-(8) will exhibit both deepness and steepness when the distribution of $u_{t}$ is asymmetric; it will also be time-irreversible unless $u_{t}$ is Gaussian.

In all simulations, we generated 2,500 series $\left\{x_{t}\right\}$ of length $n \in\{124,224\}$ from (6)-(8), with the innovations $\left\{u_{t}\right\}$ driving the stationary component $\left\{y_{t}\right\}$ being drawn from the following asymmetric distributions: (a) lognormal with $\gamma_{1} \in\{0.95,6.185\}$; (b) standard Weibull with $\gamma_{1} \in\{0.96,6.619\}$; (c) gamma with $\gamma_{1} \in\{0.943,6.325\}$; (d) member of the $S_{U}$ system with $\gamma_{1} \in\{0.99,6.172\}$ (see Johnson et al., 1994, ch. 12). In addition, Gaussian innovations were also considered to examine the properties of the tests under the null hypothesis of symmetry and time-reversibility. ${ }^{16}$

An estimate of the stationary component of $\left\{x_{t}\right\}$ was obtained by means of the HP filter (with $\lambda=1,600$ ), the BP filter (with $m=12, \omega_{1}=\pi / 16, \omega_{2}=\pi / 3$ ), and the BN decomposition. The $\mathrm{BN}$ decomposition was based on an $\operatorname{ARIMA}(2,1,2)$ model for $x_{t}$, which is the reduced form of the model in (6)-(8). ${ }^{17}$ The symmetry tests are based on the $\mathcal{S}$ statistic in (1) with $k$ selected by means of the data-based rule used in the simulation experiments in Section 2.1, the $\mathcal{C}$ statistic in (2), and the $\mathcal{R}_{\ell}$ statistic in (3) with $\ell=1$.

Table 2 reports Monte Carlo rejection frequencies of 0.05-level of skewness-based symmetry tests for $\left\{\widehat{y}_{t}\right\}$ and $\left\{\Delta \widehat{y}_{t}\right\}$, which, as explained before, are the appropriate series for testing the hypothesis of deepness and steepness, respectively. It is immediately evident that when the innovations driving the stationary component of $\left\{x_{t}\right\}$ are mildly asymmetric, tests based on HP, BP or BN detrended data have little power to detect either type of asymmetry. When $\left\{u_{t}\right\}$ come from a heavily asymmetric distribution, the performance of the tests improves considerably. In this case, tests for deepness based on BN detrended data have the highest empirical power, while HP detrending is the most successful in revealing cyclical steepness.

To investigate the extent to which low test power is the result of detrending, we also computed the empirical rejection frequencies of the symmetry test when it is applied to the true (but unobservable in practice) stationary component $\left\{y_{t}\right\}$ of $\left\{x_{t}\right\}$ and to its first-difference $\left\{\Delta y_{t}\right\}$. The relevant figures, also shown in Table 2, reveal that the power of the test generally suffers as a result of extracting the stationary component of $\left\{x_{t}\right\}$ by means of the various filters: test power is in the majority of cases higher when using the true components that are required for deepness and steepness tests, the improvement being particularly pronounced for tests of the latter type. It is also worth observing that tests for deepness based on $\left\{y_{t}\right\}$ tend to be somewhat conservative and have difficulty in rejecting symmetry when the distribution of the innovations is mildly asymmetric.

Further insights into the effects of detrending are provided by Table 3A, which records the Monte Carlo mean and standard deviation of the empirical skewness coefficient $\widetilde{\gamma}_{1}$ for the HP, BP and $\mathrm{BN}$ detrended series $\left\{\widehat{y}_{t}\right\}$ and the true stationary component $\left\{y_{t}\right\}$. As expected, since the various filters are linear, they do not introduce asymmetry in the detrended data when none is actually present. ${ }^{18}$ However, all three types of detrending tend to reduce the asymmetry in the stationary component of the series; in many cases, the average value of $\widetilde{\gamma}_{1}$ for $\left\{\widehat{y}_{t}\right\}$ is almost 2.7 times smaller than the corresponding value for the true stationary component. This is obviously responsible for the low rejection frequencies of the symmetry tests reported in Table 2. The problem also appears

\footnotetext{
${ }^{15}$ The structure and parameter values of this model reflect the results obtained by Watson (1986) for the logarithm of US GNP over the period 1949-1984.

${ }^{16}$ All distributions were recentred and rescaled to have zero mean and unit standard deviation.

${ }^{17}$ Our choice of $m=12$ for the BP filter means that 24 sample observations are lost. To ensure that results are not driven by differences in the effective sample size across different detrending methods, 12 data points were also removed from the beginning and the end of HP and BN detrended series.

${ }^{18}$ Further experiments (not reported here) also reveal this to be true when $\left\{u_{t}\right\}$ come from non-Gaussian symmetric distributions such as the Student- $t$, the double exponential, or the logistic.
} 
in the case of the first-differenced detrended series $\left\{\Delta \widehat{y}_{t}\right\}$, as the results in Table 3B show. It is particularly noteworthy that $\left\{\Delta \widehat{y}_{t}^{\mathrm{BN}}\right\}$ is almost symmetric even in cases where the true stationary component of $\left\{x_{t}\right\}$ is highly asymmetric, which explains the poor performance of steepness tests based on BN-detrended data.

The Monte Carlo rejection frequencies of 0.05-level symmetry tests for $\left\{\widehat{y}_{t}\right\}$ based on the Markovchain statistic $\mathcal{C}$ and the time-reversibility statistic $\mathcal{R}_{1}$ are reported in Table $4 .{ }^{19}$ Both tests are evidently very conservative, their empirical rejection frequencies generally being close to zero when $\left\{u_{t}\right\}$ is a Gaussian process. Furthermore, they have virtually no power to detect asymmetry, even when the innovations that drive the stationary component of $\left\{x_{t}\right\}$ are heavily asymmetric. A comparison of the rejection frequencies of tests based on the estimated cyclical component $\left\{\widehat{y}_{t}\right\}$ and the true cyclical component $\left\{y_{t}\right\}$ reveals this lack of power to be to a large extent due to detrending. If the true (but unobservable in practice) stationary component of $\left\{x_{t}\right\}$ is used, the tests (especially $\mathcal{R}_{1}$ ) have reasonable power when the sample size is large and the asymmetry of the innovations is pronounced, power which is lost with detrending. The Markov-chain test based on BP-filtered data is the most unattractive, its rejection probability being zero in the majority of the cases considered.

Finally, in order to investigate whether our results are particular to the data-generating mechanism used in the experiments, we repeated the analysis using an alternative stochastic mechanism in which asymmetry is generated by means of a nonlinear model rather than by a linear model driven by asymmetrically distributed errors. More specifically, we took $x_{t}=\xi_{t}+y_{t}$ with $\Delta \xi_{t}=0.02+0.02 \eta_{t}, \eta_{t} \sim N(0,1)$, but replaced the linear structure in (8) by the logistic smoothtransition autoregressive (LSTAR) equation

$$
\begin{aligned}
y_{t}= & 1.29 y_{t-1}-0.64 y_{t-3}-0.35 y_{t-4}+0.55 y_{t-5} \\
& +\left(0.03-0.56 y_{t-1}+0.64 y_{t-3}-0.34 y_{t-5}\right) \\
& \div\left\{1+\exp \left[-732.6\left(y_{t-2}-0.06\right)\right]\right\}+0.02 u_{t},
\end{aligned}
$$

where $\left\{u_{t}\right\}$ are i.i.d. $N(0,1)$ variates. ${ }^{20}$ The results of the experiments (based on 2,500 Monte Carlo replications) are reported in Table 5. As in the case of (6)-(8), the HP, BP and BN detrended series are considerably less asymmetric than the true stationary LSTAR component $\left\{y_{t}\right\}$ of $\left\{x_{t}\right\}$. This is reflected in the properties of deepness and steepness tests based on $\mathcal{S}$, which have little power to detect either type of asymmetry. The situation is even worse for the Markov-chain and time-reversibility tests based on $\mathcal{C}$ and $\mathcal{R}_{1}$.

\section{ASYMMETRIES IN REAL GDP}

In this section, we apply the tests discussed before to investigate the patterns of business-cycle asymmetry in real GDP series from the G7 countries, namely Canada, France, Germany, Italy, Japan, the United Kingdom, and the United States. ${ }^{21}$ Although there appears to be no consensus in the literature about the asymmetric behaviour of real output over the business cycle (the results being sensitive with respect to the test used and the time period covered by the sample), significant evidence of cyclical asymmetry does not appear to be very common. For example, US GDP has been found to be deep but not steep (Sichel, 1993; Verbrugge, 1997), while UK GDP seems to be neither (Speight and McMillan, 1998; Razzak, 2001).

\footnotetext{
${ }^{19}$ Very similar results were obtained using the time-reveribility test based on $\mathcal{R}_{\ell}$ with $\ell=2$.

${ }^{20}$ The parameter values of the LSTAR model reflect the results reported in Granger and Teräsvirta (1993, p. 155) for a model for Canadian industrial production over the period 1960-1986.

${ }^{21}$ The analysis is based on the natural logarithms of seasonally adjusted quarterly time series. The data were obtained from DATASTREAM and cover the following periods: Canada: 1961.1-1997.2; France: 1977.1-1997.2; Germany: 1960.1-1997.2; Italy: 1970.1-1997.2; Japan: 1965.1-1997.2; UK: 1955.1-1997.2; US: 1959.1-1997.2.
} 
As in the simulations of Section 3, the GDP series are detrended by means of the HP, BP and $\mathrm{BN}$ procedures; for the latter, we used $\operatorname{ARIMA}(p, 1, q)$ models the order of which was selected by minimizing the familiar Akaike information criterion (AIC) over $(p, q) \in\{0,1,2\} \times\{0,1,2\}$. The hypothesis of cyclical symmetry is then tested using the $\mathcal{S}$ statistic in (1), the $\mathcal{C}$ statistic in (2), and the $\mathcal{R}_{\ell}$ statistic in (3) with $\ell \in\{1,2\}$. The $P$-values of all test statistics were computed from a sieve bootstrap approximation to their null distribution (the details of the bootstrap procedure can be found in the Appendix).

Tables $6 \mathrm{~A}-6 \mathrm{C}$ contain the results of the tests. For four countries, namely Canada, Japan, Germany and the UK, symmetry is rejected for at least one of the three estimated cyclical series on the basis of the skewness-based test, suggesting that the business cycle is deep. ${ }^{22}$ Furthermore, business-cycle steepness does not seem to be as rare a characteristic as earlier studies have suggested, with significant values of $\mathcal{S}$ obtained for Canada, Germany, Japan and the UK on the basis of at least one of the detrended series. In the light of the generally low test power documented in Section 3, these findings are rather impressive, and it seems, therefore, reasonable to conclude that most GDP series are characterized by substantial cyclical asymmetry. ${ }^{23}$ Consistent with the results of the simulation experiments, the evidence in favour of business-cycle asymmetry is weaker when the Markov-chain and time-reversibility tests are considered. The test based on $\mathcal{C}$ rejects symmetry only in the case of the HP-filtered German GDP. The tests based on $\mathcal{R}_{1}$ and $\mathcal{R}_{2}$ reject the hypothesis of time-reversibility for the BP-filtered Canadian and US GDP, suggesting that these two series are lognitudinally asymmetric.

\section{CONCLUSION}

This paper has considered the problem of testing for symmetry in time series which have been detrended using the HP, BP and BN methods. Detrended series have been found to exhibit less asymmetry than the true cyclical component, leading to a reduction in the power of tests for symmetry of the business cycle. Markov-chain and time-reversibility tests in particular have negligible power to detect cyclical asymmetry. These results mean that failure to reject the hypothesis of cyclical symmetry should be interpreted with much caution, and make the already documented evidence in favour of business-cycle asymmetry even stronger. In our application, we have found evidence of business-cycle asymmetry in many of the GDP time series examined.

From a practitioner's viewpoint, our results provide a warning against the uncritical interpretation of results obtained after the use of detrending procedures. Unless the cycle is manifestly asymmetric, one would appear to have little hope of detecting asymmetric behaviour in estimates of the cyclical component obtained by means of HP, BP or BN filtering. This, of course, also implies that in those cases where asymmetries are detected in detrended data one can be fairly sure that the cyclical component is indeed asymmetric.

\section{APPENDIX: BOOTSTRAP TESTS}

This Appendix gives a description of the algorithm used to compute the bootstrap $P$-values for symmetry tests based on $\mathcal{S}, \mathcal{C}$ and $\mathcal{R}_{\ell}$. The assumption underlying our sieve bootstrap procedure is that the time series $\left\{y_{t}\right\}_{t=1}^{n}$ is a realization of a stationary infinite-order autoregressive process. The idea is to approximate this process by an autoregressive model of order which increases slowly with the sample size and use this to generate replicates of the observed data as in the usual residual-

\footnotetext{
${ }^{22}$ It is worth noting that since seasonal adjustment of a time series can potentially induce nonlinearity in the filtered series (see Ghysels et al., 1996), the evidence in favour of asymmetry in GDP might have been overstated here.

${ }^{23}$ It is interesting to note that a skewness-based test that uses the kernel variance estimator examined in Section 2.1 rejects symmetry only in the case of first-differenced BN-detrended Canadian GDP.
} 
based resampling schemes for autoregressive models. Since we need to approximate the sampling distributions of the test statistics under the hypothesis of symmetry, we use a variant of the sieve bootstrap in which resampling is based on a symmetrized version of the empirical distribution of the residuals from the autoregressive model fitted to the data (cf. Psaradakis, 2002).

The algorithm used to obtain bootstrap $P$-values and/or critical values for the $\mathcal{S}$ statistic can be summarized as follows.

1. Given observations $\left\{y_{t}\right\}_{t=1}^{n}$, obtain estimates $\left(\widehat{\phi}_{1}, \ldots, \widehat{\phi}_{p}\right)$ of the coefficients of an $\operatorname{AR}(p)$ model for $y_{t}-\bar{y}$, where $\bar{y}:=n^{-1} \sum_{t=1}^{n} y_{t}$ and $p$ is such that $p \rightarrow \infty$ and $p / n \rightarrow 0$ as $n \rightarrow \infty$. Then, construct a set of residuals $\left\{\widehat{\varepsilon}_{t}\right\}_{t=p+1}^{n}$ according to

$$
\widehat{\varepsilon}_{t}=\left(y_{t}-\bar{y}\right)-\sum_{i=1}^{p} \widehat{\phi}_{i}\left(y_{t-i}-\bar{y}\right), \quad t=p+1, \ldots, n .
$$

2. Take a random sample $\left\{\varepsilon_{t}^{*}\right\}_{t=-r+1-p}^{n}(r>0)$ from the empirical distribution that puts mass $\frac{1}{2}(n-p)^{-1}$ on each of $\pm \widehat{\varepsilon}_{p+1}, \ldots, \pm \widehat{\varepsilon}_{n}$ (so that, conditionally on $\left\{y_{1}, \ldots, y_{n}\right\},\left\{\varepsilon_{t}^{*}\right\}$ are symmetrically distributed about zero).

3. Generate bootstrap data $\left\{y_{t}^{*}\right\}_{t=-r+1}^{n}$ according to the recursion

$$
y_{t}^{*}-\bar{y}=\sum_{i=1}^{p} \widehat{\phi}_{i}\left(y_{t-i}^{*}-\bar{y}\right)+\varepsilon_{t}^{*}, \quad t=-r+1, \ldots, n,
$$

where $y_{t}^{*}=\bar{y}+\varepsilon_{t}^{*}$ for $t \leqslant-r$. Then calculate the bootstrap value of $\mathcal{S}$, say $\mathcal{S}^{*}$, by using the definition of $\mathcal{S}$ in (1) and the bootstrap data $\left\{y_{t}^{*}\right\}_{t=1}^{n}$ in the place of the original data $\left\{y_{t}\right\}_{t=1}^{n}$.

4. Repeat steps 2 and $3 B$ times to obtain a sample $\left\{\mathcal{S}_{b}^{*}\right\}_{b=1}^{B}$ of $\mathcal{S}^{*}$ values. The bootstrap $P$-value of the observed realization $\widehat{\mathcal{S}}$ of $\mathcal{S}$ is then computed as

$$
B^{-1} \sum_{b=1}^{B} \mathbf{1}\left(\left|\mathcal{S}_{b}^{*}\right| \geqslant|\widehat{\mathcal{S}}|\right) .
$$

The 100 $(1-\alpha)$ th sample percentile of $\left\{\mathcal{S}_{b}^{*}\right\}_{b=1}^{B}$ yields a critical value of significance level $\alpha$ for $\mathcal{S}$.

The bootstrap $P$-values for the Markov-chain $(\mathcal{C})$ and time-irreversibility $\left(\mathcal{R}_{\ell}\right)$ test statistics are computed in an analogous manner. In the case of the latter statistic, however, the bootstrap replicates $\left\{\varepsilon_{t}^{*}\right\}$ are drawn from the $N\left(0, \widehat{\sigma}_{\varepsilon}^{2}\right)$ distribution, with $\widehat{\sigma}_{\varepsilon}^{2}=(n-2 p)^{-1} \sum_{t=p+1}^{n} \widehat{\varepsilon}_{t}^{2}$, instead of the symmetrized empirical distribution of $\left\{\widehat{\varepsilon}_{t}\right\}_{t=p+1}^{n}$. This is essential since time-reversibility of linear processes is a typically Gaussian property (cf. Hallin et al., 1988). Following Bühlmann (1997), the autoregressive order $p$ in step 1 of the bootstrap algorithm is selected by minimizing the AIC in the range $0 \leqslant p \leqslant 10 \log _{10} n$. The number of bootstrap replications is $B=299$ in Monte Carlo experiments, while $B=999$ is used in the empirical application of Section 4.

\section{ACKNOWLEDGEMENTS}

The authors are grateful to Fabio Canova, John Driffill, Finn Kydland and Morten Ravn for helpful conversations on the issues discussed in this paper, and to two anonymous referees for useful comments on an earlier draft.

\section{REFERENCES}

1. Acemoglu, D., and A. Scott (1997), 'Asymmetric Business Cycles: Theory and Time-Series Evidence', Journal of Monetary Economics, 40, 501-533. 
2. Andrews, D. W. K., and J. C. Monahan (1992), 'An Improved Heteroskedasticity and Autocorrelation Consistent Covariance Matrix Estimator', Econometrica, 60, 953-966.

3. Baxter, M., and R. G. King (1999), 'Measuring Business Cycles: Approximate Band-Pass Filters for Economic Time Series', Review of Economics and Statistics, 81, 575-593.

4. Beaudry, P., and G. M. Koop (1993), 'Do Recessions Permanently Change Output?', Journal of Monetary Economics, 31, 149-163.

5. Beveridge, S., and C.R. Nelson (1981), 'A New Approach to Decomposition of Economic Time Series into Permanent and Transitory Components with particular Attention to Measurement of the "Business Cycle", Journal of Monetary Economics, 7, 151-174.

6. Bickel, P. J., and P. Bühlmann (1997), 'Closure of Linear Processes', Journal of Theoretical Probability, 10, 445-479.

7. Boldin, M.D. (1999), 'Should Policy Makers Worry about Asymmetries in the Business Cycle?', Studies in Nonlinear Dynamics and Econometrics, 3, 203-220.

8. Bühlmann, P. (1997), 'Sieve Bootstrap for Time Series', Bernoulli, 3, 123-148.

9. Burns, A. M., and W. C. Mitchell (1946), Measuring Business Cycles, New York: National Bureau of Economic Research.

10. Caballero, R. J., and E. M. R. A. Engel (1991), 'Dynamic (S, s) Economies', Econometrica, 59, $1659-1686$.

11. Canova, F. (1998), 'Detrending and Business Cycle Facts', Journal of Monetary Economics, 41, 475-512.

12. Chalkley, M., and I. H. Lee (1998), 'Learning and Asymmetric Business Cycles', Review of Economic Dynamics, 1, 623-645.

13. Chen, Y.-T., Chou, R.Y., and C.-M. Kuan (2000), 'Testing Time Reversibility Without Moment Restrictions', Journal of Econometrics, 95, 199-218.

14. Christiano, L. J., and W. J. den Haan (1996), 'Small-Sample Properties of GMM for Business-Cycle Analysis', Journal of Business and Economic Statistics, 14, 309-327.

15. Cogley, T., and J. M. Nason (1995), 'Effects of the Hodrick-Prescott Filter on Trend and Difference Stationary Time Series: Implications for Business Cycle Research', Journal of Economic Dynamics and Control, 19, 253278.

16. DeLong, J.B., and L.H. Summers (1986), 'Are Business Cycles Symmetrical?', in Gordon, R.J. (ed.), The American Business Cycle: Continuity and Change, Chicago: University of Chicago Press, pp. 166-179.

17. Falk, B. (1986), 'Further Evidence on the Asymmetric Behavior of Economic Time Series over the Business Cycle', Journal of Political Economy, 94, 1096-1109.

18. Famma, E. F. (1990), 'Stock Returns, Expected Returns, and Real Activity', Journal of Finance, 45, 1089-1108.

19. Famma, E.F., and K.R. French (1989), 'Business Conditions and Expected Returns on Stocks and Bonds', Journal of Financial Economics, 25, 23-49.

20. Ferson, W. E., and J. J. Merrick (1987), 'Non-stationary and Stage-of-the-Business-Cycle Effects in ConsumptionBased Asset Pricing Relations', Journal of Financial Economics, 18, 124-145.

21. Gasser, T. (1975), 'Goodness-of-Fit Tests for Correlated Data', Biometrika, 62, 563-570.

22. Ghysels, E., Granger, C. W. J., and P. L. Siklos (1996), 'Is Seasonal Adjustment a Linear or Nonlinear DataFiltering Process?', Journal of Business and Economic Statistics, 14, 374-386.

23. Giles, D.E.A. (1997), 'Testing for Asymmetry in the Measured and Underground Business Cycles in New Zealand', Economic Record, 72, 225-232.

24. Granger, C.W.J., and T. Teräsvirta (1993), Modelling Nonlinear Economic Relationships, Oxford: Oxford University Press.

25. Hallin, M., Lefevre, C., and M. L. Puri (1988), 'On Time-Reversibility and the Uniqueness of Moving Average Representations for Non-Gaussian Stationary Time Series', Biometrika, 75, 170-171.

26. Hamilton, J.D. (1989), 'A New Approach to the Economic Analysis of Nonstationary Time Series and the Business Cycle', Econometrica, 57, 357-384.

27. Harding D., and A. Pagan (2002), 'Dissecting the Cycle: A Methodological Investigation', Journal of Monetary Economics, 49, 365-381.

28. Harvey, A.C., and A. Jaeger (1993), 'Detrending, Stylized Facts and the Business Cycle', Journal of Applied Econometrics, 8, 231-247. 
29. Hodrick, R. J., and E. C. Prescott (1997), 'Post-War U.S. Business Cycles: An Empirical Investigation', Journal of Money, Credit, and Banking, 29, 1-16.

30. Johnson, N.L., Kotz, S., and N. Balakrishnan (1994), Continuous Univariate Distributions, Vol. 1, Second Edition, New York: Wiley.

31. Keynes, J. M. (1936), The General Theory of Employment, Interest, and Money, London: Macmillan.

32. Kim, M.-J., and J.-S. Yoo (1995), 'New Index of Coincidence Indicators: A Multivariate Markov Switching Factor Model Approach', Journal of Monetary Economics, 36, 607-630.

33. King, R. G., and S. T. Rebelo (1993), 'Low Frequency Filtering and Real Business Cycles', Journal of Economic Dynamics and Control, 17, 207-231.

34. Kreiss, J.-P. (1997), 'Asymptotic Properties of Residual Bootstrap for Autoregressions', manuscript, Institut für Mathematische Stochastik, Technische Universität Braunschweig.

35. Maravall, A. (1995), 'Unobserved Components in Economic Time Series', in Pesaran, M.H., and M. Wickens (eds.), Handbook of Applied Econometrics, Oxford: Blackwell, pp. 12-72.

36. McNevin, B., and S.N. Neftçi (1992), 'Some Evidence on the Non-Linearity of Economic Time Series: 18901981', in Benhabib, J. (ed.), Cycles and Chaos in Economic Equilibrium, Princeton: Princeton University Press, pp. 429-445.

37. McQueen, G., and S.R. Thorley (1993), 'Asymmetric Business Cycle Turning Points', Journal of Monetary Economics, 31, 341-362.

38. Neftçi, S. N. (1984), 'Are Economic Time Series Asymmetric over the Business Cycle?', Journal of Political Economy, 92, 307-328.

39. Newbold, P. (1990), 'Precise and Efficient Computation of the Beveridge-Nelson Decomposition of Economic Time Series', Journal of Monetary Economics, 26, 453-457.

40. Psaradakis, Z. (2002), 'A Bootstrap Test for Symmetry of Dependent Data Based on a Kolmogorov-Smirnov Type Statistic', Communications in Statistics-Simulation and Computation, forthcoming.

41. Ramsey, J. B., and P. Rothman (1996), 'Time Irreversibility and Business Cycle Asymmetry', Journal of Money, Credit, and Banking, 28, 1-21.

42. Ravn, M. O., and H. Uhlig (1997), 'On Adjusting the HP-Filter for the Frequency of Observations', Discussion Paper No. 9750, CentER, Tilburg University.

43. Razzak, W.A. (2001), 'Business Cycle Asymmetries: International Evidence', Review of Economic Dynamics, 4, 230-243.

44. Sichel, D. E. (1989), 'Are Business Cycle Asymmetric? A Correction', Journal of Political Economy, 97, 12551260.

45. Sichel, D. E. (1993), 'Business Cycle Asymmetry: A Deeper Look', Economic Inquiry, 31, 224-236.

46. Speight, A.E.H., and D. G. McMillan (1998), 'Testing for Asymmetries in UK Macroeconomic Time Series', Scottish Journal of Political Economy, 45, 158-170.

47. Verbrugge, R. (1997), 'Investigating Cyclical Asymmetries', Studies in Nonlinear Dynamics and Econometrics, $2,15-22$.

48. Watson, M. W. (1986), 'Univariate Detrending Methods with Stochastic Trends', Journal of Monetary Economics, 18, 49-75.

49. Westlund, A., and S. Öhlén (1991), 'On Testing for Symmetry in Business Cycles', Empirical Economics, 16, $479-502$. 
Table 1. Asymptotic Variance Estimators

\begin{tabular}{lcccccc}
\hline & & \multicolumn{2}{c}{ Estimator } & & \multicolumn{2}{c}{ Test } \\
\cline { 3 - 4 } \cline { 6 - 7 } Model & Exact Var. & Gasser & Kernel & & Gasser & Kernel \\
\hline & & \multicolumn{3}{c}{$n=100$} \\
$\mathrm{M}_{1}$ & 0.052 & 0.057 & 0.131 & & 0.044 & 0.000 \\
$\mathrm{M}_{2}$ & 0.045 & 0.050 & 0.186 & & 0.041 & 0.000 \\
$\mathrm{M}_{3}$ & 0.030 & 0.035 & 0.344 & & 0.052 & 0.000 \\
$\mathrm{M}_{4}$ & 0.052 & 0.060 & 0.177 & & 0.037 & 0.000 \\
$\mathrm{M}_{5}$ & 0.017 & 0.022 & 0.026 & & 0.036 & 0.018 \\
& & & $n=200$ & & \\
$\mathrm{M}_{1}$ & 0.029 & 0.029 & 0.070 & & 0.042 & 0.001 \\
$\mathrm{M}_{2}$ & 0.024 & 0.026 & 0.100 & & 0.048 & 0.000 \\
$\mathrm{M}_{3}$ & 0.015 & 0.017 & 0.177 & & 0.045 & 0.000 \\
$\mathrm{M}_{4}$ & 0.029 & 0.031 & 0.095 & & 0.043 & 0.000 \\
$\mathrm{M}_{5}$ & 0.009 & 0.010 & 0.014 & & 0.046 & 0.013 \\
\hline
\end{tabular}

Notes: Entries give the sampling variance of $\widetilde{\gamma}_{1}$, the average estimated variance, and the fraction of Monte Carlo replications in which the relevant test statistic exceeds the 95th percentile of the $\chi_{1}^{2}$ distribution. 
Table 2. Rejection Frequencies of a Test Based on $\mathcal{S}$

\begin{tabular}{|c|c|c|c|c|c|c|c|c|c|}
\hline Innovations & $\gamma_{1}$ & $y_{t}$ & $\widehat{y}_{t}^{\mathrm{HP}}$ & $\widehat{y}_{t}^{\mathrm{BP}}$ & $\widehat{y}_{t}^{\mathrm{BN}}$ & $\Delta y_{t}$ & $\Delta \widehat{y}_{t}^{\mathrm{HP}}$ & $\Delta \widehat{y}_{t}^{\mathrm{BP}}$ & $\Delta \widehat{y}_{t}^{\mathrm{BN}}$ \\
\hline & & \multicolumn{8}{|c|}{$n=124$} \\
\hline Normal & 0.000 & 0.022 & 0.030 & 0.031 & 0.051 & 0.038 & 0.037 & 0.034 & 0.046 \\
\hline \multirow[t]{2}{*}{ Lognormal } & 0.950 & 0.036 & 0.041 & 0.045 & 0.108 & 0.367 & 0.162 & 0.050 & 0.086 \\
\hline & 6.185 & 0.364 & 0.224 & 0.243 & 0.464 & 0.984 & 0.630 & 0.278 & 0.312 \\
\hline \multirow[t]{2}{*}{ Weibull } & 0.960 & 0.038 & 0.033 & 0.036 & 0.100 & 0.429 & 0.139 & 0.043 & 0.081 \\
\hline & 6.619 & 0.499 & 0.276 & 0.312 & 0.531 & 0.992 & 0.700 & 0.365 & 0.371 \\
\hline \multirow[t]{2}{*}{ Gamma } & 0.943 & 0.039 & 0.039 & 0.044 & 0.108 & 0.405 & 0.162 & 0.043 & 0.084 \\
\hline & 6.325 & 0.647 & 0.316 & 0.369 & 0.606 & 0.997 & 0.788 & 0.429 & 0.427 \\
\hline \multirow[t]{3}{*}{$S_{U}$} & 0.990 & 0.038 & 0.042 & 0.046 & 0.114 & 0.391 & 0.171 & 0.055 & 0.088 \\
\hline & 6.172 & 0.364 & 0.224 & 0.243 & 0.464 & 0.983 & 0.630 & 0.278 & 0.311 \\
\hline & & \multicolumn{8}{|c|}{$n=224$} \\
\hline Normal & 0.000 & 0.030 & 0.039 & 0.040 & 0.065 & 0.044 & 0.048 & 0.045 & 0.058 \\
\hline \multirow[t]{2}{*}{ Lognormal } & 0.950 & 0.092 & 0.068 & 0.078 & 0.176 & 0.684 & 0.289 & 0.084 & 0.122 \\
\hline & 6.185 & 0.736 & 0.446 & 0.483 & 0.692 & 0.999 & 0.885 & 0.536 & 0.501 \\
\hline \multirow[t]{2}{*}{ Weibull } & 0.960 & 0.092 & 0.072 & 0.076 & 0.165 & 0.748 & 0.305 & 0.086 & 0.115 \\
\hline & 6.619 & 0.883 & 0.550 & 0.590 & 0.761 & 1.000 & 0.932 & 0.653 & 0.542 \\
\hline \multirow[t]{2}{*}{ Gamma } & 0.943 & 0.087 & 0.068 & 0.072 & 0.170 & 0.687 & 0.288 & 0.088 & 0.118 \\
\hline & 6.325 & 0.958 & 0.639 & 0.694 & 0.810 & 0.999 & 0.959 & 0.731 & 0.593 \\
\hline \multirow[t]{2}{*}{$S_{U}$} & 0.090 & 0.098 & 0.072 & 0.081 & 0.184 & 0.713 & 0.305 & 0.089 & 0.125 \\
\hline & 6.172 & 0.732 & 0.445 & 0.483 & 0.690 & 0.999 & 0.884 & 0.535 & 0.500 \\
\hline
\end{tabular}

Notes: Entries are the fraction of Monte Carlo replications in which $\mathcal{S}$ exceeds the 95th percentile of the $\chi_{1}^{2}$ distribution. 
Table 3A. Sampling Properties of $\widetilde{\gamma}_{1}$

\begin{tabular}{lccccc}
\hline Innovations & $\gamma_{1}$ & $y_{t}$ & $\widehat{y}_{t}^{\mathrm{HP}}$ & $\widehat{y}_{t}^{\mathrm{BP}}$ & $\widehat{y}_{t}^{\mathrm{BN}}$ \\
\hline \multirow{2}{*}{ Normal } & & & \multicolumn{2}{c}{$n=124$} \\
Lognormal & 0.000 & $-0.011[0.415]$ & $-0.005[0.320]$ & $-0.008[0.350]$ & $-0.002[0.406]$ \\
& 6.185 & $-0.904[0.617]$ & $-0.400[0.468]$ & $-0.478[0.518]$ & $-0.288[0.904]$ \\
Weibull & 0.960 & $-0.234[0.419]$ & $-0.110[0.314]$ & $-0.129[0.343]$ & $-0.066[0.527]$ \\
& 6.619 & $-1.090[0.606]$ & $-0.476[0.485]$ & $-0.567[0.541]$ & $-0.301[1.008]$ \\
Gamma & 0.943 & $-0.216[0.423]$ & $-0.107[0.323]$ & $-0.126[0.349]$ & $-0.080[0.537]$ \\
& 6.325 & $-1.277[0.570]$ & $-0.522[0.467]$ & $-0.631[0.516]$ & $-0.396[1.068]$ \\
$S_{U}$ & 0.990 & $-0.241[0.431]$ & $-0.112[0.331]$ & $-0.136[0.361]$ & $-0.086[0.498]$ \\
& 6.172 & $-0.902[0.617]$ & $-0.400[0.468]$ & $-0.477[0.518]$ & $-0.287[0.905]$ \\
Normal & 0.000 & $0.001[0.340]$ & $0.003[0.242]$ & $0.004[0.264]$ & $0.004[0.595]$ \\
Lognormal & 0.950 & $-0.269[0.353]$ & $-0.116[0.254]$ & $-0.138[0.276]$ & $-0.089[0.619]$ \\
& 6.185 & $-1.181[0.666]$ & $-0.515[0.448]$ & $-0.605[0.494]$ & $-0.305[1.045]$ \\
Weibull & 0.960 & $-0.287[0.345]$ & $-0.121[0.248]$ & $-0.145[0.267]$ & $-0.093[0.583]$ \\
& 6.619 & $-1.435[0.679]$ & $-0.613[0.472]$ & $-0.721[0.522]$ & $-0.367[1.150]$ \\
Gamma & 0.943 & $-0.263[0.355]$ & $-0.126[0.240]$ & $-0.150[0.259]$ & $-0.081[0.537]$ \\
& 6.325 & $-1.577[0.600]$ & $-0.678[0.448]$ & $-0.799[0.495]$ & $-0.388[1.164]$ \\
$S_{U}$ & 0.990 & $-0.280[0.355]$ & $-0.121[0.255]$ & $-0.144[0.277]$ & $-0.093[0.620]$ \\
& 6.172 & $-1.179[0.666]$ & $-0.514[0.448]$ & $-0.604[0.494]$ & $-0.307[1.044]$ \\
\hline
\end{tabular}

Notes: The entries give the Monte Carlo mean and standard deviation (in square brackets) of $\widetilde{\gamma}_{1}$. 
Table 3B. Sampling Properties of $\widetilde{\gamma}_{1}$

\begin{tabular}{|c|c|c|c|c|c|}
\hline Innovations & $\gamma_{1}$ & $\Delta y_{t}$ & $\Delta \widehat{y}_{t}^{\mathrm{HP}}$ & $\Delta \widehat{y}_{t}^{\mathrm{BP}}$ & $\Delta \widehat{y}_{t}^{\mathrm{BN}}$ \\
\hline & & \multicolumn{4}{|c|}{$n=124$} \\
\hline Normal & 0.000 & $0.015[0.262]$ & $0.007[0.231]$ & $0.015[0.300]$ & $-0.008[0.353]$ \\
\hline \multirow[t]{2}{*}{ Lognormal } & 0.950 & $-0.465[0.321]$ & $-0.221[0.263]$ & $-0.104[0.311]$ & $-0.007[0.424]$ \\
\hline & 6.185 & $-1.772[0.863]$ & $-0.823[0.756]$ & $-0.431[0.480]$ & $-0.014[0.705]$ \\
\hline \multirow[t]{2}{*}{ Weibull } & 0.960 & $-0.503[0.271]$ & $-0.231[0.244]$ & $-0.122[0.298]$ & $0.003[0.465]$ \\
\hline & 6.619 & $-2.169[0.868]$ & $-0.968[0.806]$ & $-0.513[0.481]$ & $-0.006[0.804]$ \\
\hline \multirow[t]{2}{*}{ Gamma } & 0.943 & $-0.490[0.298]$ & $-0.229[0.251]$ & $-0.105[0.301]$ & $-0.004[0.426]$ \\
\hline & 6.325 & $-2.531[0.799]$ & $-1.098[0.758]$ & $-0.590[0.466]$ & $-0.034[0.805]$ \\
\hline \multirow[t]{3}{*}{$S_{U}$} & 0.990 & $-0.484[0.327]$ & $-0.230[0.266]$ & $-0.109[0.312]$ & $-0.007[0.426]$ \\
\hline & 6.172 & $-1.768[0.863]$ & $-0.821[0.756]$ & $-0.430[0.479]$ & $-0.013[0.704]$ \\
\hline & & \multicolumn{4}{|c|}{$n=224$} \\
\hline Normal & 0.000 & $0.004[0.186]$ & $0.002[0.170]$ & $0.003[0.223]$ & $0.003[0.571]$ \\
\hline \multirow[t]{2}{*}{ Lognormal } & 0.950 & $-0.505[0.244]$ & $-0.243[0.197]$ & $-0.128[0.233]$ & $-0.009[0.579]$ \\
\hline & 6.185 & $-2.143[0.989]$ & $-1.044[0.831]$ & $-0.557[0.459]$ & $-0.021[0.816]$ \\
\hline \multirow[t]{2}{*}{ Weibull } & 0.960 & $-0.521[0.207]$ & $-0.251[0.183]$ & $-0.141[0.224]$ & $-0.017[0.544]$ \\
\hline & 6.619 & $-2.568[0.959]$ & $-1.219[0.864]$ & $-0.668[0.468]$ & $-0.030[0.897]$ \\
\hline \multirow[t]{2}{*}{ Gamma } & 0.943 & $-0.494[0.220]$ & $-0.245[0.192]$ & $-0.137[0.231]$ & $-0.013[0.480]$ \\
\hline & 6.325 & $-2.836[0.823]$ & $-1.338[0.775]$ & $-0.735[0.453]$ & $-0.017[0.900]$ \\
\hline \multirow[t]{2}{*}{$S_{U}$} & 0.990 & $-0.526[0.249]$ & $-0.254[0.200]$ & $-0.133[0.234]$ & $-0.009[0.578]$ \\
\hline & 6.172 & $-2.138[0.980]$ & $-1.043[0.830]$ & $-0.556[0.459]$ & $-0.022[0.815]$ \\
\hline
\end{tabular}

Notes: The entries give the Monte Carlo mean and standard deviation (in square brackets) of $\widetilde{\gamma}_{1}$. 
Table 4. Rejection Frequencies of Tests Based on $\mathcal{C}$ and $\mathcal{R}_{1}$

\begin{tabular}{|c|c|c|c|c|c|c|c|c|c|}
\hline \multirow[b]{2}{*}{ Innovations } & \multirow[b]{2}{*}{$\gamma_{1}$} & \multicolumn{4}{|c|}{$\mathcal{C}$} & \multicolumn{4}{|c|}{$\mathcal{R}_{1}$} \\
\hline & & $y_{t}$ & $\widehat{y}_{t}^{\mathrm{HP}}$ & $\widehat{y}_{t}^{\mathrm{BP}}$ & $\widehat{y}_{t}^{\mathrm{BN}}$ & $y_{t}$ & $\widehat{y}_{t}^{\mathrm{HP}}$ & $y_{t}^{\mathrm{BP}}$ & $\widehat{y}_{t}^{\mathrm{BN}}$ \\
\hline & & \multicolumn{8}{|c|}{$n=124$} \\
\hline Normal & 0.000 & 0.005 & 0.015 & 0.001 & 0.048 & 0.002 & 0.002 & 0.002 & 0.020 \\
\hline \multirow[t]{2}{*}{ Lognormal } & 0.950 & 0.026 & 0.023 & 0.000 & 0.052 & 0.018 & 0.007 & 0.001 & 0.025 \\
\hline & 6.185 & 0.202 & 0.056 & 0.000 & 0.058 & 0.372 & 0.071 & 0.010 & 0.030 \\
\hline \multirow[t]{2}{*}{ Weibull } & 0.960 & 0.032 & 0.026 & 0.000 & 0.049 & 0.036 & 0.010 & 0.002 & 0.021 \\
\hline & 6.619 & 0.406 & 0.062 & 0.000 & 0.069 & 0.589 & 0.105 & 0.018 & 0.040 \\
\hline \multirow[t]{2}{*}{ Gamma } & 0.943 & 0.026 & 0.021 & 0.000 & 0.054 & 0.024 & 0.012 & 0.005 & 0.028 \\
\hline & 6.325 & 0.700 & 0.076 & 0.001 & 0.078 & 0.731 & 0.145 & 0.021 & 0.042 \\
\hline \multirow[t]{3}{*}{$S_{U}$} & 0.990 & 0.027 & 0.023 & 0.000 & 0.053 & 0.020 & 0.007 & 0.001 & 0.024 \\
\hline & 6.172 & 0.202 & 0.056 & 0.000 & 0.057 & 0.370 & 0.072 & 0.010 & 0.030 \\
\hline & & \multicolumn{8}{|c|}{$n=224$} \\
\hline Normal & 0.000 & 0.004 & 0.008 & 0.000 & 0.034 & 0.001 & 0.001 & 0.002 & 0.020 \\
\hline \multirow[t]{2}{*}{ Lognormal } & 0.950 & 0.027 & 0.025 & 0.000 & 0.038 & 0.053 & 0.022 & 0.003 & 0.031 \\
\hline & 6.185 & 0.480 & 0.088 & 0.001 & 0.006 & 0.846 & 0.226 & 0.032 & 0.050 \\
\hline \multirow[t]{2}{*}{ Weibull } & 0.960 & 0.038 & 0.022 & 0.000 & 0.041 & 0.086 & 0.029 & 0.008 & 0.036 \\
\hline & 6.619 & 0.824 & 0.096 & 0.000 & 0.073 & 0.958 & 0.296 & 0.060 & 0.063 \\
\hline \multirow[t]{2}{*}{ Gamma } & 0.943 & 0.031 & 0.021 & 0.000 & 0.033 & 0.066 & 0.023 & 0.005 & 0.024 \\
\hline & 6.325 & 0.984 & 0.112 & 0.001 & 0.068 & 0.988 & 0.391 & 0.078 & 0.065 \\
\hline \multirow[t]{2}{*}{$S_{U}$} & 0.090 & 0.028 & 0.026 & 0.000 & 0.037 & 0.061 & 0.024 & 0.003 & 0.034 \\
\hline & 6.172 & 0.475 & 0.089 & 0.001 & 0.058 & 0.842 & 0.225 & 0.032 & 0.051 \\
\hline
\end{tabular}

Notes: Entries are the fraction of Monte Carlo replications in which $|\mathcal{C}|$ and $\left|\mathcal{R}_{1}\right|$ exceed the 97.5th percentile of the $N(0,1)$ distribution.

Table 5. Results of Experiments with LSTAR Cycles

\begin{tabular}{lcccccccc}
\hline & $y_{t}$ & $\widehat{y}_{t}^{\mathrm{HP}}$ & $\widehat{y}_{t}^{\mathrm{BP}}$ & $\widehat{y}_{t}^{\mathrm{BN}}$ & $\Delta y_{t}$ & $\Delta \widehat{y}_{t}^{\mathrm{HP}}$ & $\Delta \widehat{y}_{t}^{\mathrm{BP}}$ & $\Delta \widehat{y}_{t}^{\mathrm{BN}}$ \\
\hline & & & & $n=124$ \\
Mean of $\widetilde{\gamma}_{1}$ & -0.583 & -0.214 & -0.280 & 0.082 & 0.305 & 0.140 & 0.263 & -0.022 \\
Std. Dev. of $\widetilde{\gamma}_{1}$ & 0.396 & 0.336 & 0.364 & 0.394 & 0.257 & 0.236 & 0.249 & 0.239 \\
Test Power: $\mathcal{S}$ & 0.264 & 0.109 & 0.124 & 0.206 & 0.311 & 0.107 & 0.220 & 0.070 \\
Test Power: $\mathcal{C}$ & 0.005 & 0.010 & 0.000 & 0.027 & - & - & - & - \\
Test Power: $\mathcal{R}_{1}$ & 0.026 & 0.007 & 0.004 & 0.010 & - & - & - & - \\
& & & & $n=224$ & & & & \\
Mean of $\widetilde{\gamma}_{1}$ & -0.669 & -0.246 & -0.317 & 0.077 & 0.324 & 0.142 & 0.277 & -0.017 \\
Std. Dev. of $\widetilde{\gamma}_{1}$ & 0.312 & 0.263 & 0.282 & 0.373 & 0.194 & 0.174 & 0.183 & 0.178 \\
Test Power: $\mathcal{S}$ & 0.584 & 0.210 & 0.260 & 0.380 & 0.546 & 0.162 & 0.426 & 0.101 \\
Test Power: $\mathcal{C}$ & 0.006 & 0.009 & 0.000 & 0.014 & - & - & - & - \\
Test Power: $\mathcal{R}_{1}$ & 0.058 & 0.012 & 0.011 & 0.013 & - & - & - & - \\
\hline
\end{tabular}

Notes: The entries give the Monte Carlo mean and standard deviation of $\widetilde{\gamma}_{1}$, and the fraction of Monte Carlo replications in which $\mathcal{S}$ exceeds the 95 th percentile of the $\chi_{1}^{2}$ distribution and $|\mathcal{C}|$ and $\left|\mathcal{R}_{1}\right|$ exceed the 97.5 th percentile of the $N(0,1)$ distribution. 
Table 6A. Symmetry Tests for HP-Filtered Real GDP

\begin{tabular}{|c|c|c|c|c|c|c|c|}
\hline Country & $\widetilde{\gamma}_{1}\left(\widehat{y}_{t}^{\mathrm{HP}}\right)$ & $\widetilde{\gamma}_{1}\left(\Delta \widehat{y}_{t}^{\mathrm{HP}}\right)$ & $\mathcal{S}\left(\widehat{y}_{t}^{\mathrm{HP}}\right)$ & $\mathcal{S}\left(\Delta \widehat{y}_{t}^{\mathrm{HP}}\right)$ & $\mathcal{C}$ & $\mathcal{R}_{1}$ & $\mathcal{R}_{2}$ \\
\hline Canada & -0.633 & 0.008 & $\begin{array}{c}3.930 \\
{[0.037]}\end{array}$ & $\begin{array}{c}0.002 \\
{[0.976]}\end{array}$ & $\begin{array}{c}0.192 \\
{[0.813]}\end{array}$ & $\begin{array}{c}0.539 \\
{[0.451]}\end{array}$ & $\begin{array}{c}0.687 \\
{[0.305]}\end{array}$ \\
\hline France & -0.124 & -0.160 & $\begin{array}{c}0.069 \\
{[0.709]}\end{array}$ & $\begin{array}{c}0.366 \\
{[0.729]}\end{array}$ & $\begin{array}{l}-0.604 \\
{[0.485]}\end{array}$ & $\begin{array}{c}0.527 \\
{[0.439]}\end{array}$ & $\begin{array}{c}0.693 \\
{[0.272]}\end{array}$ \\
\hline Germany & 0.392 & 1.094 & $\begin{array}{c}2.089 \\
{[0.515]}\end{array}$ & $\begin{array}{c}28.71 \\
{[0.001]}\end{array}$ & $\begin{array}{l}-1.782 \\
{[0.039]}\end{array}$ & $\begin{array}{l}-0.686 \\
{[0.382]}\end{array}$ & $\begin{array}{l}-0.640 \\
{[0.296]}\end{array}$ \\
\hline Italy & 0.477 & -0.268 & $\begin{array}{c}1.613 \\
{[0.203]}\end{array}$ & $\begin{array}{c}1.382 \\
{[0.268]}\end{array}$ & $\begin{array}{l}-0.504 \\
{[0.483]}\end{array}$ & $\begin{array}{c}0.392 \\
{[0.464]}\end{array}$ & $\begin{array}{c}0.334 \\
{[0.560]}\end{array}$ \\
\hline Japan & 0.673 & -0.767 & $\begin{array}{c}3.652 \\
{[0.107]}\end{array}$ & $\begin{array}{c}13.22 \\
{[0.003]}\end{array}$ & $\begin{array}{l}-0.422 \\
{[0.654]}\end{array}$ & $\begin{array}{l}-0.262 \\
{[0.693]}\end{array}$ & $\begin{array}{l}-0.102 \\
{[0.875]}\end{array}$ \\
\hline UK & 0.452 & 0.671 & $\begin{array}{c}3.304 \\
{[0.259]}\end{array}$ & $\begin{array}{c}13.43 \\
{[0.001]}\end{array}$ & $\begin{array}{l}-1.458 \\
{[0.124]}\end{array}$ & $\begin{array}{l}-0.007 \\
{[0.994]}\end{array}$ & $\begin{array}{l}-0.213 \\
{[0.754]}\end{array}$ \\
\hline US & -0.320 & -0.135 & $\begin{array}{c}1.097 \\
{[0.325]}\end{array}$ & $\begin{array}{c}0.467 \\
{[0.467]}\end{array}$ & $\begin{array}{c}0.903 \\
{[0.237]}\end{array}$ & $\begin{array}{l}-0.033 \\
{[0.953]}\end{array}$ & $\begin{array}{c}0.413 \\
{[0.484]}\end{array}$ \\
\hline
\end{tabular}

Note: Figures in square brackets are bootstrap $P$-values.

Table 6B. Symmetry Tests for BP-Filtered Real GDP

\begin{tabular}{|c|c|c|c|c|c|c|c|}
\hline Country & $\widetilde{\gamma}_{1}\left(\widehat{y}_{t}^{\mathrm{BP}}\right)$ & $\widetilde{\gamma}_{1}\left(\Delta \widehat{y}_{t}^{\mathrm{BP}}\right)$ & $\mathcal{S}\left(\widehat{y}_{t}^{\mathrm{BP}}\right)$ & $\mathcal{S}\left(\Delta \widehat{y}_{t}^{\mathrm{BP}}\right)$ & $\mathcal{C}$ & $\mathcal{R}_{1}$ & $\mathcal{R}_{2}$ \\
\hline Canada & -0.670 & -0.840 & $\begin{array}{c}2.630 \\
{[0.099]}\end{array}$ & $\begin{array}{c}7.424 \\
{[0.007]}\end{array}$ & $\begin{array}{c}0.355 \\
{[0.488]}\end{array}$ & $\begin{array}{c}1.251 \\
{[0.035]}\end{array}$ & $\begin{array}{c}1.258 \\
{[0.028]}\end{array}$ \\
\hline France & 0.055 & -0.164 & $\begin{array}{c}0.008 \\
{[0.914]}\end{array}$ & $\begin{array}{c}0.144 \\
{[0.611]}\end{array}$ & $\begin{array}{l}-0.485 \\
{[0.342]}\end{array}$ & $\begin{array}{l}-0.260 \\
{[0.651]}\end{array}$ & $\begin{array}{l}-0.280 \\
{[0.626]}\end{array}$ \\
\hline Germany & 0.428 & 0.490 & $\begin{array}{c}1.227 \\
{[0.212]}\end{array}$ & $\begin{array}{c}2.413 \\
{[0.149]}\end{array}$ & $\begin{array}{l}-0.292 \\
{[0.610]}\end{array}$ & $\begin{array}{l}-0.027 \\
{[0.966]}\end{array}$ & $\begin{array}{l}-0.027 \\
{[0.977]}\end{array}$ \\
\hline Italy & 0.434 & -0.222 & $\begin{array}{c}0.979 \\
{[0.311]}\end{array}$ & $\begin{array}{c}0.683 \\
{[0.453]}\end{array}$ & $\begin{array}{c}0.027 \\
{[0.939]}\end{array}$ & $\begin{array}{c}0.541 \\
{[0.326]}\end{array}$ & $\begin{array}{c}0.360 \\
{[0.478]}\end{array}$ \\
\hline Japan & 1.024 & -0.718 & $\begin{array}{c}4.933 \\
{[0.079]}\end{array}$ & $\begin{array}{c}5.367 \\
{[0.005]}\end{array}$ & $\begin{array}{c}0.395 \\
{[0.320]}\end{array}$ & $\begin{array}{c}0.633 \\
{[0.422]}\end{array}$ & $\begin{array}{c}0.571 \\
{[0.421]}\end{array}$ \\
\hline UK & 0.402 & 0.381 & $\begin{array}{c}1.208 \\
{[0.196]}\end{array}$ & $\begin{array}{c}2.230 \\
{[0.088]}\end{array}$ & $\begin{array}{c}0.611 \\
{[0.164]}\end{array}$ & $\begin{array}{c}0.119 \\
{[0.851]}\end{array}$ & $\begin{array}{c}0.137 \\
{[0.817]}\end{array}$ \\
\hline US & -0.327 & -0.440 & $\begin{array}{c}0.796 \\
{[0.361]}\end{array}$ & $\begin{array}{c}1.914 \\
{[0.145]}\end{array}$ & $\begin{array}{c}0.858 \\
{[0.127]}\end{array}$ & $\begin{array}{c}1.310 \\
{[0.028]}\end{array}$ & $\begin{array}{c}1.243 \\
{[0.036]}\end{array}$ \\
\hline
\end{tabular}

Note: Figures in square brackets are bootstrap $P$-values. 
Table 6C. Symmetry Tests for BN-Detrended Real GDP

\begin{tabular}{|c|c|c|c|c|c|c|c|}
\hline Country $(p, q)$ & $\widetilde{\gamma}_{1}\left(\widehat{y}_{t}^{\mathrm{BN}}\right)$ & $\widetilde{\gamma}_{1}\left(\Delta \widehat{y}_{t}^{\mathrm{BN}}\right)$ & $\mathcal{S}\left(\widehat{y}_{t}^{\mathrm{BN}}\right)$ & $\mathcal{S}\left(\Delta \widehat{y}_{t}^{\mathrm{BN}}\right)$ & $\mathcal{C}$ & $\mathcal{R}_{1}$ & $\mathcal{R}_{2}$ \\
\hline Canada $(0,1)$ & 0.421 & 0.263 & $\begin{array}{c}4.203 \\
{[0.205]}\end{array}$ & $\begin{array}{c}2.588 \\
{[0.074]}\end{array}$ & $\begin{array}{l}-0.260 \\
{[0.799]}\end{array}$ & $\begin{array}{l}-1.061 \\
{[0.254]}\end{array}$ & $\begin{array}{l}-1.106 \\
{[0.174]}\end{array}$ \\
\hline France $(0,2)$ & -0.094 & 0.156 & $\begin{array}{c}0.096 \\
{[0.709]}\end{array}$ & $\begin{array}{c}0.427 \\
{[0.499]}\end{array}$ & $\begin{array}{c}-1.416 \\
{[0.169]}\end{array}$ & $\begin{array}{l}-1.026 \\
{[0.186]}\end{array}$ & $\begin{array}{c}-0.446 \\
{[0.507]}\end{array}$ \\
\hline Germany $(0,1)$ & -1.382 & -0.423 & $\begin{array}{c}43.75 \\
{[0.000]}\end{array}$ & $\begin{array}{c}5.443 \\
{[0.010]}\end{array}$ & $\begin{array}{l}-1.076 \\
{[0.187]}\end{array}$ & $\begin{array}{c}1.202 \\
{[0.187]}\end{array}$ & $\begin{array}{l}-0.165 \\
{[0.820]}\end{array}$ \\
\hline Italy $(0,2)$ & 0.234 & -0.210 & $\begin{array}{c}0.973 \\
{[0.345]}\end{array}$ & $\begin{array}{c}0.908 \\
{[0.402]}\end{array}$ & $\begin{array}{c}-0.533 \\
{[0.547]}\end{array}$ & $\begin{array}{c}0.790 \\
{[0.344]}\end{array}$ & $\begin{array}{c}0.329 \\
{[0.637]}\end{array}$ \\
\hline Japan ( & 0.85 & -1.053 & $\begin{array}{c}1.873 \\
{[0.108]}\end{array}$ & $\begin{array}{c}24.47 \\
{[0.008]}\end{array}$ & $\begin{array}{l}-1.040 \\
{[0.276]}\end{array}$ & $\begin{array}{c}0.071 \\
{[0.886]}\end{array}$ & $\begin{array}{c}0.174 \\
{[0.711]}\end{array}$ \\
\hline $\mathrm{UK}(0,1)$ & -0.616 & 0.105 & $\begin{array}{c}11.01 \\
{[0.001]}\end{array}$ & $\begin{array}{c}0.439 \\
{[0.587]}\end{array}$ & $\begin{array}{c}0.144 \\
{[0.876]}\end{array}$ & $\begin{array}{l}-1.209 \\
{[0.183]}\end{array}$ & $\begin{array}{c}0.137 \\
{[0.845]}\end{array}$ \\
\hline ) & -0.144 & 0 & $\begin{array}{c}0.475 \\
{[0.687]}\end{array}$ & $\begin{array}{c}2.582 \\
{[0.136]}\end{array}$ & $\begin{array}{c}0.416 \\
{[0.670]}\end{array}$ & $\begin{array}{l}-1.566 \\
{[0.070]}\end{array}$ & $\begin{array}{l}-0.258 \\
{[0.710]}\end{array}$ \\
\hline
\end{tabular}

Note: Figures in square brackets are bootstrap $P$-values. 